\title{
Assessment of Vulnerability for Land Degradation
}

Sodgerel. P (Ph.D), Narantuya.A, , Amarmend.Ch, Erdenechimeg.A, Purvee.L(Ph.D)

Engineering Department, School of Agroecology and Business, MULS

sodgerel@sab.edu.mn

\begin{abstract}
Many scientists agreed that land degradation is caused by multiple forces, including extreme weather conditions particularly drought, and human activities that overgrazing in Mongolia. Geographic information system (GIS) have an important role in linkage and analysis of all aspects, in particular for determine land degradation risk. This paper describes four risk performance indicators and their attribute data tables of air temperature, rainfall, carrying capacity, road density were compiled into the digital geomorphologic map units in a geographic information system. As result this study, the very high risk area was present in $0,03 \%$ and moderate hazardous area was $52,6 \%$, low risk area was $47.3 \%$.
\end{abstract}

Keywords: Land degradation, Arkhangai province, risk assessment

\section{Introduction}

Land degradation is considered one of the most severe global problems worldwide. Desertification, is a form of land degradation, by which fertile land becomes desert. Desertification includes land degradation in arid, semiarid and dry subhumid areas resulting from various factors, including climatic variations and human activities (UNCCD, 1994). According to this definition, over 90 percent of the total amount of territory in Mongolia is vulnerability for desertification as a result of climate change, land use and human activities. Land degradation is increasing in severity and extent in many parts of Mongolia, with more than $72 \%$ of total area of grasslands undergoing degradation which mainly caused by overgrazing.

In Mongolia, land degradation and desertification processes result from both human activities and climatic variability. Overgrazing has long been considered the primary cause of degradation in Mongolia but it is now thought that rainfall variability and long-term drought are more important determinants.

It is important to integrate both climatic variability and human activities due to interpret land degradation as spatial level. A large number of studies have been carried out using different methods of remote sensing and geographic information system (GIS) to determine land degradation risk. GIS and remote sensing have an important role in linkage and analysis of solid base line data on natural resources (soils, physiography, climate, vegetation, land use, etc.) and on socio-economic aspects, in particular for detection (direct or indirect), extrapolation and interpretation, area calculation, and monitoring. Furthermore, GIS is appropriate for identifying and mapping land degradation risks and planning strategies for sustainable land management.

The aims of this study are to: (1) formulate and develop vulnerability indicators and criteria (2) produce the climatic and degradation maps of the study area using remote sensing and GIS techniques, (3) assess the risk of land degradation depending on GIS spatial analysis

\section{Material and Methods}

\subsection{Study area}

Arkhangai aimag is situated in the central part of the Khangai mountain range and its territory comprises mountains, steppe and plains as covers $55,313.82 \mathrm{~km}^{2}$. In winter mean temperature is $-30^{\circ} \mathrm{C}$ to $-38^{\circ} \mathrm{C}$ and in summer the highest temperature is between $25^{\circ} \mathrm{C}$ and $36^{\circ} \mathrm{C}$. Over 70 percent of the territory of the aimag is 
pasture land, almost 2 percent with hay fields, about 1 percent with sown area, and 15 percent of the territory is covered with deciduous and coniferous forest.
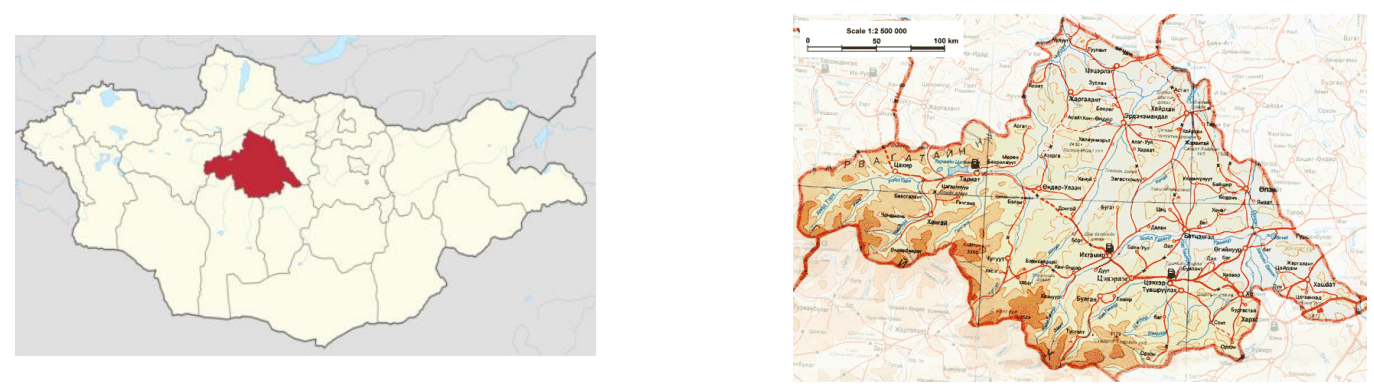

Figure 1. Map of Arkhangai province

\subsection{Spatial analysis and map creation}

The research was undertaken on the basis of climatic data (air temperature, precipitation) on growing season that derived from Institute of Meteorology and Hydrology and information about carrying capacity of rangeland, roads using remotely sensed data. All that data used GIS spatial analysis methods (interpolation, buffering, density, reclassify, weighted overlay) using ArcMap 9.3 to produce spatial distribution of climatic and degradation risk maps which classified by high risk, moderate risk and low risk.

The method presented here links into a broader framework of multi-criteria analysis. Climatic variability classified by their values on plant growing whereas rangeland carrying capacity classified by percent of overgrazing and the crossroad $(\mathrm{km})$ in $1 \mathrm{~km}^{2}$ is less than 0.25 for low, $0.25-0.50$ for medium and $0.50-0.75$ for severe by Kaurechiv I.S, respectively. In this framework the main methodological steps which can be conceptualized as shown following;

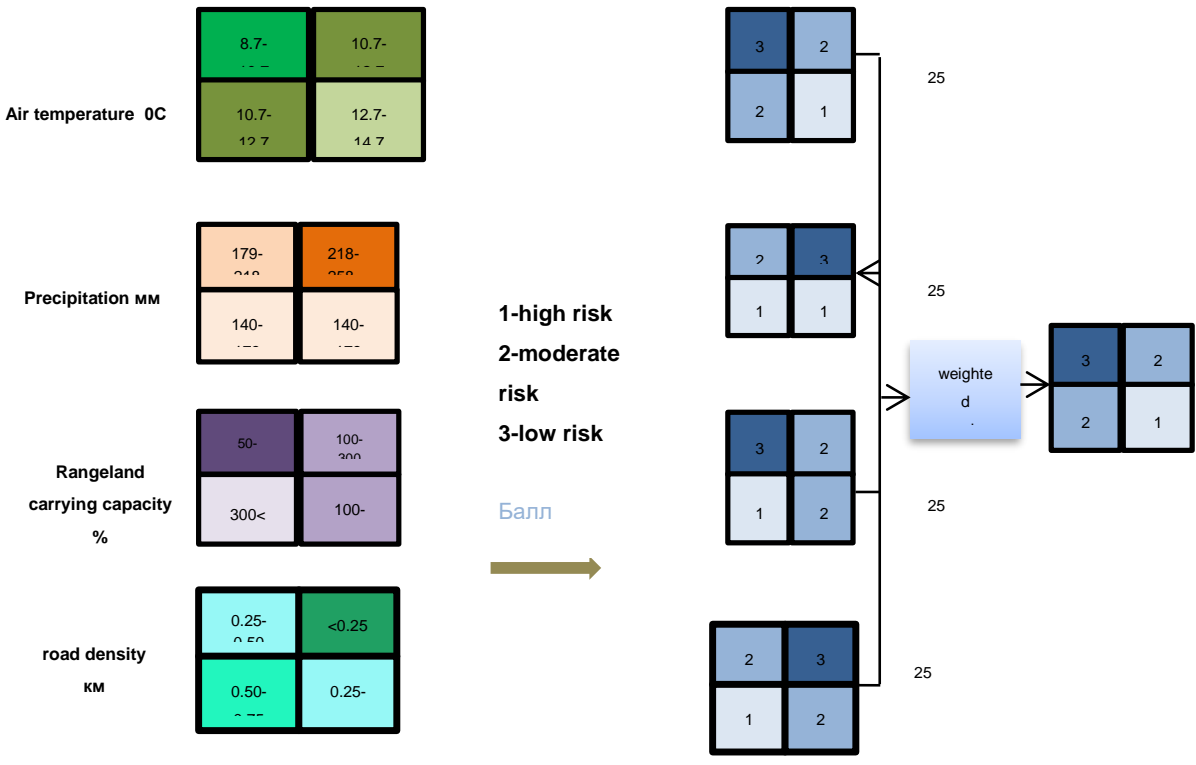

Figure 2. Designed of land degradation risk model. 


\section{Result}

The risk of degradation is governed by several factors i.e. air temperature, precipitation, carrying capacity of rangeland, road density.

\subsection{Air temperature}

Air temperature of warm season is significantly affect rangeland's plant growth. In past five years, air temperature of total provincial area in the warm season was relatively high in 2010 .

GIS interpolation method used to display and produce spatial distribution of air temperature map in Arkhangai province. Air temperature is higher $1-2^{\circ} \mathrm{C}$ than average past 5 years in Khangai, Olziit, Khashaat soum. The last 5 years in heating season (May, June, July, Aug, Sept), average air temperature was $8^{\circ} \mathrm{C}-10^{\circ} \mathrm{C}$ in Tsahir, Khangai, Tariat soum while Ulziit, Ugi Nuur, Khotont, Khashaat soum was $12^{\circ} \mathrm{C}-14^{\circ} \mathrm{C}$ ( figure 3 ).

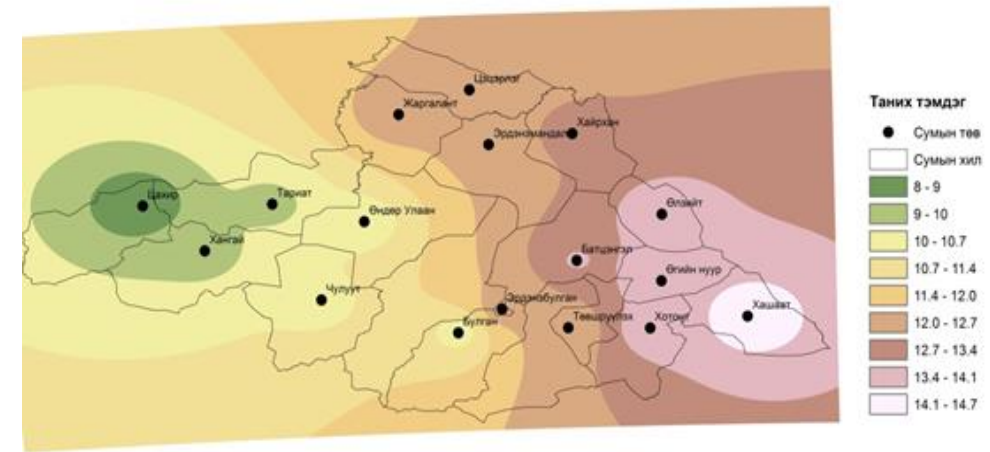

Figure 3. Air temperature distribution of warm season in Arkhangai province

\subsection{Precipitation}

The lowest annual precipitation was $51-177 \mathrm{~mm}$ in 2014 and significantly higher than total average rainfall was in 2012.

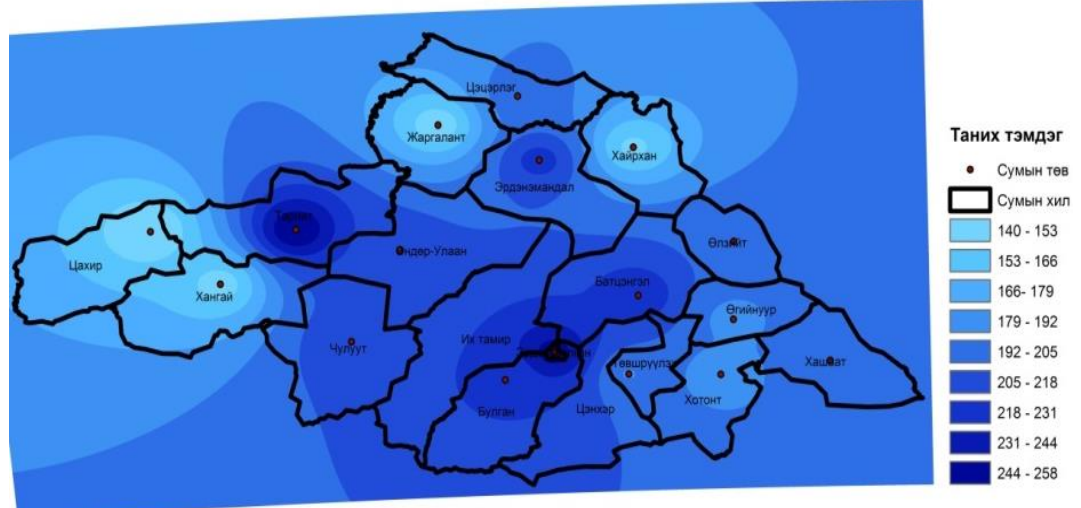

Figure 4. Rainfall distribution of warm season in Arkhangai province

Distribution of rainfall varies considerably between provincial area. Total rainfall of Khangai, Jargalant, Hairhan, Ogii Lake, Khotont soum was less than $192 \mathrm{~mm}$ and Tariat, Erdenebulgan, Erdenemandal soum was more than $205 \mathrm{~mm}$ of rainfall.

\subsection{Rangeland carrying capacity}


Arkhangai province has 4292768 livestock in 2014 which is leading the country. The number of livestock was relatively stable until 1996, has risen steadily 2 times over the last 10 years. Herd structure of sheep and goats is a major place. The reason of growing the number of livestock is increasing cashmere prices, transition to a market economy and developed private property that has become a major influence for lacking rangeland.

Many scientists address that rangeland plant species changing and dominated by inedible or poisonous plants due to increasing the livestock.

The rangeland carrying capacity of Arkhangai province is varies considerably between provincial area depending on number of livestock, area of rangeland, plant harvest (figure 5).

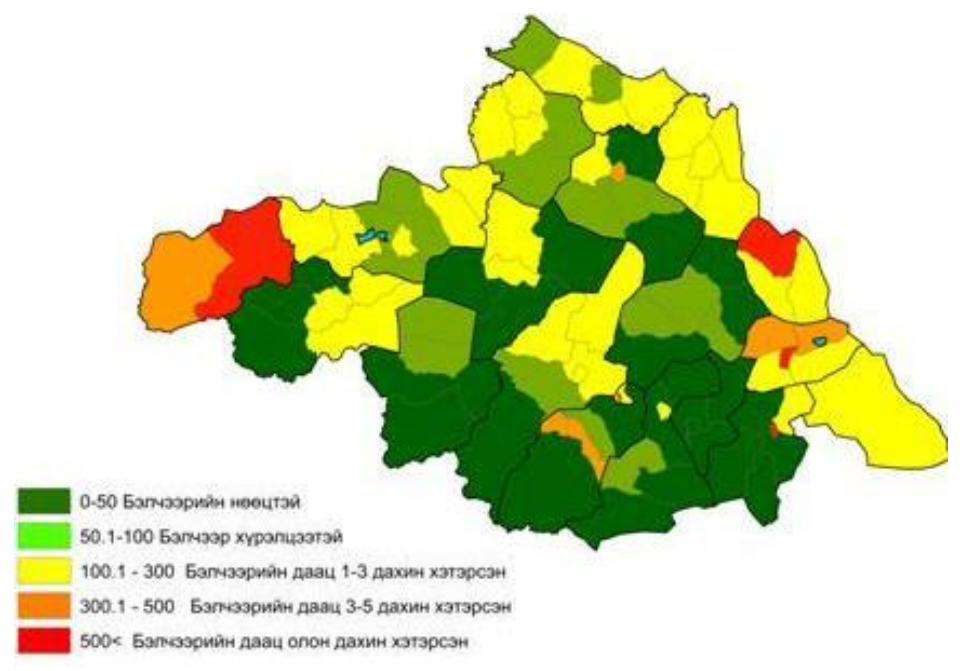

Figure 5. Rangeland carrying capacity of Arkhangai province

Figure 5 shown as area of sufficient for grazing colored by green, 1-3 times overgrazing which colored by yellow, 3-5 times overgrazing which colored by orange and more than 5 times overgrazing area that colored by red.

\subsection{Intensity of crossroad}

Most developed tourist region has high density of crossroad that effect adverse impact for land degradation. Especially eastern part of Arkhangai is high density of crossroad in Khashaat, Ikh tamir, Ogii Lake, Khotont soum where developed by tourism.

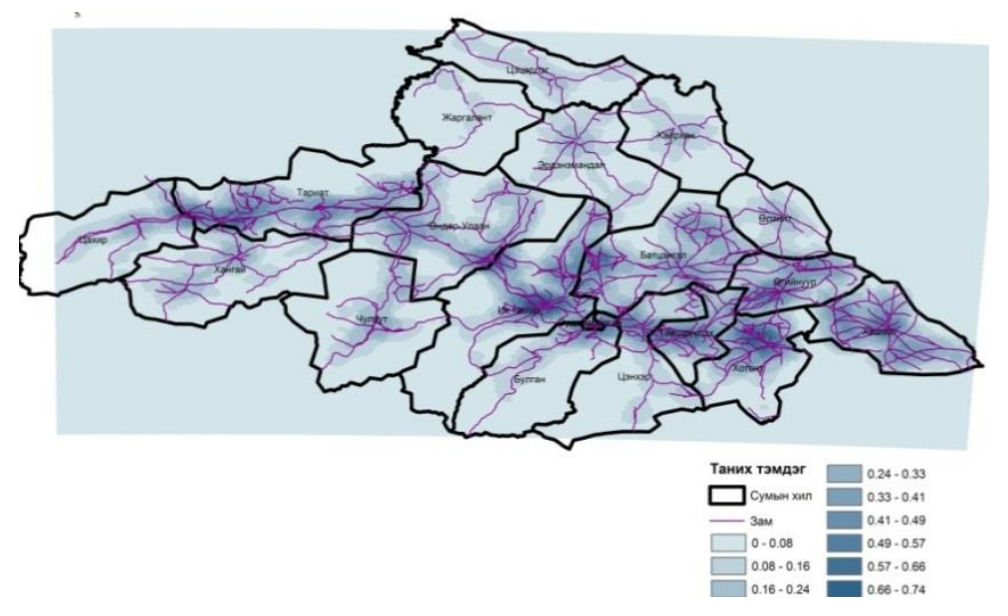

Figure 6. Crossroad density of Arkhangai province 


\subsection{Land degradation vulnerability assessment}

The attribute data tables of air temperature, rainfall, carrying capacity, road density were compiled into the digital geomorphologic map units in a geographic information system. The incorporated attributes were used to obtain the thematic layers of spatial distribution of the above mentioned characteristics (Figure 3 , Figure 4 Figure 5 and Figure 6 ). The very high hazard of land degradation was $0,03 \%$ of the total area as colored by red and moderate hazard of land degradation area was $52,6 \%$ colored by yellow and low risk area was $47.3 \%$.

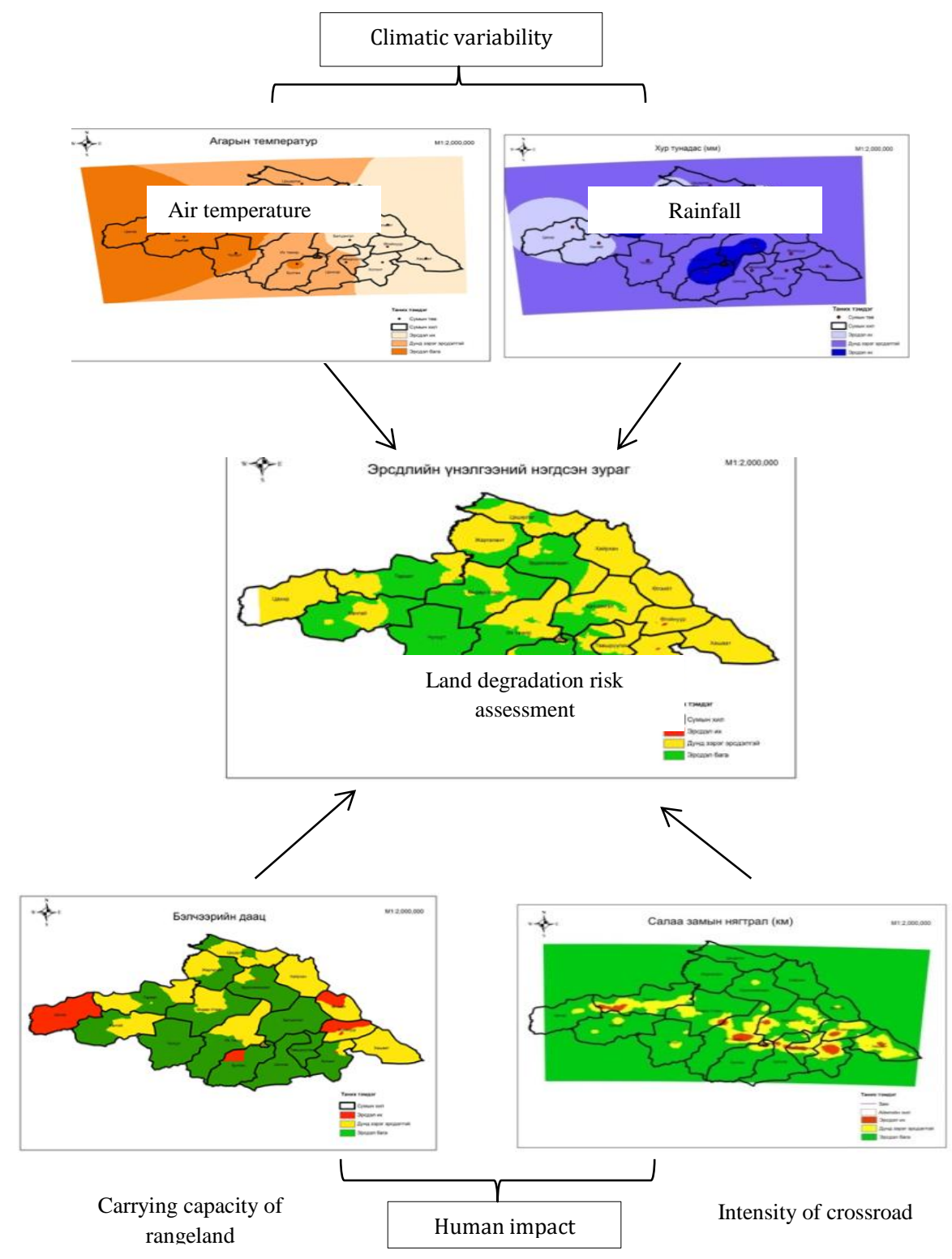

\section{Conclusion}

Understanding the spatial distribution of climate and their relation with the human impact is the key to conclude that a significant area in degradation risk due to setting the appropriate land management. The study has demonstrated that the severity and susceptibility of land degradation can be studied by harnessing technologies such as remote sensing and GIS by using spatial analyses techniques. Climatic variability and human impact on land degradation processes could be reflected in view of degradation risk and the actual hazard. Where, the research indicated that about $0.03 \%$ and $52.6 \%$ of the total area were characterized by high and moderate risk of land degradation, respectively. The present scenario of land degradation in the study area is very alarming especially in tourist developed area and needs proper land use planning and management. Furthermore, to 
study frequency of disaster and inter-linkages of disaster, risk, and development. Development of effective risk assessment to success of strategies of sustainable land management is essential.

\section{REFERENCES}

1. Masoudi, M. and Elhaeesahar, M.: Trend assessment of climate changes in Khuzestan Province, Iran, Natural Environment Change, 2, 143-152, 2016.

2. FAO: Land degradation in South Asia: its Severity Causes and Effects Upon the People, FAO, UNDP and UNEP report, Rome, 1994.

3. FAO: Land Resource Potential and Constraints at Regional and Country Levels, World Soil Resources Reports 90, FAO, Land and Water Development Division, Rome, 114 p., 2000.

4. FAO: Land Degradation Assessment in Drylands: LADA, FAO, Rome, 2002.

5. FAO-UNEP: Provisional Methodology for Assessment and Mapping of Desertification, FAO, Rome, 84 p., 1984

6. Chuluun,T.(2009). Desertification and land degradation on Mongolia, report. Ulaanbaatar

7. Risk management - Methodology of risk assessment, Mongolian standard MNS ISO 31010:2016

8. Saaty, T. L. (2008). Decision making with the analytic hierarchy process . Int. J. Services Sciences, Vol. 1, No. $1,83-106$

9. Dr. Le Canh DINH, A. P. (). GIS and analytic hierarchy process for land evaluation

10. UNEP (United Nations Environmental Program): World Atlas of Desertification, editorial commentary by: Middleton, N. and Thomas, D. S. G., Arnold, London, 1992 